\title{
A cheese-containing diet modulates immune responses and alleviates dextran sodium sulfate-induced colitis in mice
}

\author{
T. Hosoya, A. Ogawa, F. Sakai, and Y. Kadooka ${ }^{1}$ \\ Milk Science Institute, Megmilk Snow Brand Co. Ltd., 1-1-2 Minamidai, Kawagoe, Saitama, 350-1165, Japan
}

\begin{abstract}
Diet has a significant effect on immune and inflammatory responses. To date, no studies have described how consumption of a diet containing a relatively high amount of cheese affects immune responses and the inflammatory status of the body. We examined these responses in normal mice and mice with dextran sodium sulfate (DSS)-induced colitis associated with increased inflammatory responses, using a diet containing approximately $44 \%$ of a whole cheese powder and a diet containing casein, lard, and corn oil as the control. In normal mice, consumption of the cheese-containing diet induced regulatory $\mathrm{T}$ cells $\left(\mathrm{T}_{\text {reg }}\right)$, which regulate immune and inflammatory responses, and suppressed the production of IL-17, IL-4, and IL-10 in Peyer's patch cells from the intestine. The $\mathrm{T}_{\text {reg }}$ population and cytokine production were not altered in spleen cells. In mice with DSS-induced colitis, consumption of the cheesecontaining diet alleviated the symptoms of colitis, as evidenced by prevention of body weight loss and colon length shortening, and inhibition of an increase in the disease activity index, which includes diarrhea and fecal bleeding. This relief of clinical symptoms was also associated with decreased production of proinflammatory cytokines (IL-17 and IL-6) and increased production of the antiinflammatory cytokine transforming growth factor- $\beta 1$ in Peyer's patch cells. The $\mathrm{T}_{\text {reg }}$ population was reduced by consumption of the cheese-containing diet in Peyer's patch cells and spleen cells, which might reflect the alleviated symptoms of colitis. Consumption of the cheese-containing diet compared with the control diet enhanced antiinflammatory and immune regulatory responses in normal mice and in a DSS-colitis mouse model.
\end{abstract}

Key words: cheese, immune system, regulatory $\mathrm{T}$ cell, experimental colitis

Received July 26, 2011.

Accepted January 22, 2012

${ }^{1}$ Corresponding author: y-kadooka@meg-snow.com

\section{INTRODUCTION}

Cheese is produced through fermentation and ripening of milk from various mammals and has been consumed throughout a long history in food culture. Its various health-promoting effects have been well studied; for example, bioactive peptides with antihypertensive and antioxidative activities produced during the fermentation and ripening processes have been reported (Saito et al., 2000; Gómez-Ruiz et al., 2004; Higurashi et al., 2007); antihypertensive, antiobesity, anticaries, and anticarcinogenic effects have also been examined (Walther et al., 2008). However, no study has yet described the effects of consumption of a diet containing a relatively high amount of cheese on immune responses and inflammatory status of the body.

Inflammatory bowel disease (IBD) is an inflammatory disorder characterized by chronic and relapsing inflammation of the gastrointestinal tract, symptoms of which include abdominal pain, diarrhea, rectal bleeding, and BW loss. Some studies have suggested that westernization of the diet might be associated with an increase in the prevalence of IBD (Asakura et al., 2008; Goh and Xiao, 2009), and some case-control studies have reported that fruits, vegetables, and dietary fiber are protective factors, whereas sugar and fat are risk factors (Persson et al., 1992; Reif et al., 1997; Sakamoto et al., 2005). An increase in the prevalence of IBD has become a problem in developed and developing nations (Goh and Xiao, 2009).

Although the etiology and pathogenesis of IBD are not fully understood, complex interactions between the intestinal immune system and environmental factors, such as food and commensal bacteria, are considered critical (Hanauer, 2006). In mice with dextran sodium sulfate (DSS)-induced colitis, a representative mouse model of IBD, inappropriate macrophage activation, alterations of the intestinal flora, and direct toxic actions of the negative electric charge of DSS on the intestinal epithelial cells are thought to underlie the development of colitis (Okayasu et al., 1990; Kitajima et al., 1999; Ariake et al., 2000).

The mechanism of IBD is often studied using mouse models of experimental colitis, including the DSSinduced colitis model, in which the contribution of 
regulatory $\mathrm{T}$ cells $\left(\mathbf{T}_{\text {reg }}\right)$ to the alleviation of intestinal inflammation has been considered crucial (Liu et al., 2003; Mottet et al., 2003; Huber et al., 2004). The $\mathrm{T}_{\text {reg }}$, a population of $\mathrm{CD} 4^{+} \mathrm{T}$ cells defined by expression of the transcription factor forkhead box P3 (Foxp3), which is essential for their differentiation and regulatory function (Fontenot et al., 2003; Hori et al., 2003), control immune and inflammatory responses by inhibiting the proliferation and cytokine production of other T cells (Sakaguchi et al., 2006).

Because diet has a significant effect on immune and inflammatory responses, we examined how a diet containing a relatively high amount of cheese, approximately $44 \%$ of whole cheese powder, affected responses in normal mice and mice with DSS-induced colitis, compared with a diet containing casein, lard, and corn oil as the control. Analyses were carried out on the degree of colitis and the production of several representative cytokines (proinflammatory markers IL-17 and IL-6 and antiinflammatory markers TGF- $\beta 1$ and IL-10) in mice with DSS-induced colitis. We also measured IL- 4 and IFN- $\gamma$ in normal mice to examine the immune balance. Induction of $\mathrm{T}_{\text {reg }}$ that regulate inflammatory responses was determined in both mice strains.

\section{MATERIALS AND METHODS}

\section{Mice}

Five-week-old male C57BL/6J mice were purchased from Charles River Japan (Yokohama, Japan) and acclimated for 1 wk with free access to a basic diet (the AIN-76 diet; American Institute of Nutrition, 1977) and water. Each mouse was maintained in a stainlesssteel cage under controlled conditions of temperature, humidity, and light $\left(23 \pm 2^{\circ} \mathrm{C}\right.$ temperature, $50 \pm 10 \%$ humidity, and 12-h light-dark cycle). Experiments were carried out in accordance with the NIH Guide for the Care and Use of Laboratory Animals (National Research Council, 1996).

\section{Reagents and Antibodies}

Dextran sodium sulfate (molecular mass 36,00050,000 ) was purchased from MP Biomedicals (Solon, $\mathrm{OH})$, and RPMI-1640 medium, heat-inactivated fetal bovine serum (FBS), HEPES buffer, L-glutamine, penicillin, and streptomycin were purchased from Invitrogen (Carlsbad, CA). 2-Mercaptoethanol and sodium azide were purchased from Wako Pure Chemical Industries (Osaka, Japan). Fluorescein isothiocyanate (FITC) anti-mouse CD4 (clone L3T4) antibody, phycoerythrin (PE) anti-mouse/rat Foxp3 (clone FJK-16s) antibody, and anti-mouse CD16/CD32 (Fc block) antibody were purchased from eBioscience (San Diego, CA).

\section{Diets}

Two types of experimental diets, the cheese and control diets, were prepared in accordance with the AIN-76 formula with modifications, as shown in Table 1. A Gouda-type cheese, which was manufactured using Lactobacillus helveticus with high protease activity as a starter culture (Tan et al., 1995), was ripened for 6 mo at the Nakashibetsu plant of Megmilk Snow Brand (Tokyo, Japan). The cheese was freeze-dried and pulverized using a food-processor, and contents of protein equivalent (calculated from the total $\mathrm{N}$ content determined by Kjeldahl analysis), fat (acid hydrolysis method), carbohydrate (subtracting the weight of $\mathrm{CP}$, total fat, moisture, and ash from the total weight), moisture (oven drying method), and major minerals (inductively coupled plasma atomic emission spectroscopy) were analyzed. The cheese powder was added to the cheese diet at $43.9 \%$, bringing the protein equivalent and fat content in the diet to $20 \%$ and $19.4 \%$, respectively. The control diet was prepared by the addition of acid casein, an ingredient commonly used in experimental diets (Oriental Yeast Co., Tokyo, Japan) at 20\% and fat at $19.4 \%$ (lard: $17.3 \%$, corn oil: $2.1 \%$ ). The amounts of major minerals, sodium, potassium, calcium, magnesium, phosphorus and iron were corrected by adding individual raw materials of the minerals, so the nutrient composition was identical between the control and cheese diets.

\section{Experimental Protocol}

To assess the immunomodulatory effect of consumption of the cheese-containing diet on normal mice, 20 mice (6-wk-old) were divided into 2 groups of 10 mice, each with almost identical mean BW: (1) mice fed the control diet (control group) and (2) mice fed the cheese diet (cheese group). After feeding for $5 \mathrm{wk}$, mice were killed and dissected under anesthesia: the spleen was removed and Peyer's patches visible to the naked eye on the small intestinal wall were carefully dissected out with fine scissors to obtain immune cells.

To study the effect of consumption of the cheese-containing diet on DSS-induced colitis, 30 mice (6-wk-old) were divided into 3 groups of 10 mice, each with almost identical mean BW: (1) DSS-untreated mice fed the control diet (non-DSS group), (2) DSS-treated mice fed the control diet (DSS group), and (3) DSS-treated mice fed the cheese diet (DSS + cheese group). After feeding for $5 \mathrm{wk}$, experimental colitis was induced in the DSS and DSS + cheese groups by adding DSS to drinking water at a concentration of $2 \%$ (wt/vol) for $7 \mathrm{~d}$ (from $\mathrm{d}$ 0 to 7 ). The non-DSS group received ordinary drinking water without DSS. Mice were observed daily for BW, 
water and food consumption, stool consistency, and the presence of blood in the feces. Occult blood in feces was detected using the fecal occult blood kit (Shionogi, Osaka, Japan). The severity of colitis was represented as the disease activity index (DAI). The DAI was calculated based on a scoring method reported by Mchenga et al. (2008), which scores each status of BW loss, stool consistency, and bleeding separately on a scale of 0 to 4. These scores were summed to represent the DAI, which ranged from 0 to 12 . On $\mathrm{d} 7$, mice were killed and dissected under anesthesia, and the colon, spleen, and Peyer's patches were removed. Blood was collected from the inferior vena cava. Serum was separated by centrifugation at $1,000 \times g$ for $10 \mathrm{~min}$, and then stored at $-80^{\circ} \mathrm{C}$ until cytokine assays.

\section{Cell Isolation}

Spleen and Peyer's patches were mechanically disrupted in a cell culture medium (RPMI-1640) containing $10 \%$ heat-inactivated FBS, $10 \mathrm{~m} M$ HEPES buffer, $2 \mathrm{~m} M$ L-glutamine, $100 \mathrm{U} / \mathrm{mL}$ of penicillin, $100 \mu \mathrm{g} /$ $\mathrm{mL}$ streptomycin, and $0.05 \mathrm{~m} M$ 2-mercaptoethanol. Cell suspensions thus prepared were filtered through 70- $\mu \mathrm{m}$ cell strainers (BD Biosciences, San Jose, CA). Erythrocytes remaining in the spleen cell preparation were eliminated by density-gradient centrifugation with Lympholyte-M (Cedarlane Laboratories, Burlington, Ontario, Canada) according to the manufacturer's protocol. Cells were washed twice, resuspended in the cell culture medium, and stored on ice until cytokine assays or flow cytometry analysis.

\section{Stimulation of Immune Cells for Cytokine Assays}

The spleen and Peyer's patch cells were stimulated with beads conjugated with anti-mouse CD3 and CD28 antibodies to induce the production of cytokines from $\mathrm{T}$ cells (Trickett and Kwan, 2003). Isolated spleen cells and Peyer's patch cells were resuspended in the cell culture medium and cultured in 96-well cell culture plates (Asahi Glass, Tokyo, Japan) at $2.5 \times 10^{5}$ cells per well at $37^{\circ} \mathrm{C}$ in a humidified atmosphere of $5 \% \mathrm{CO}_{2}$. Spleen cells were stimulated for $48 \mathrm{~h}$ with anti-CD3/CD28-conjugated beads (Invitrogen, Carlsbad, CA) at a bead-to-cell ratio of 1:1. Peyer's patch cells were stimulated under the same conditions except that they were stimulated for $72 \mathrm{~h}$. After stimulation, all supernatants were harvested and stored at $-80^{\circ} \mathrm{C}$ until cytokine assays.

\section{Flow Cytometry}

For analysis of Foxp $3^{+} \mathrm{T}_{\text {reg }}$, spleen cells and Peyer's patch cells were stained for extracellular CD4 and in- tracellular Foxp3. Cells $\left(1 \times 10^{6}\right)$ were washed with staining buffer (PBS containing 1\% heat-inactivated FBS and $0.05 \%$ sodium azide) and incubated with FITC anti-mouse CD4 antibody $\left(0.25 \mu \mathrm{g} / 1 \times 10^{6}\right.$ cells) and anti-mouse CD16/CD32 antibody $(0.5 \mu \mathrm{g} / 1$ $\times 10^{6}$ cells) for $30 \mathrm{~min}$ at $4^{\circ} \mathrm{C}$. After washing in the staining buffer, cells were incubated in $1 \times$ fixation/ permeabilization buffer (eBioscience) overnight at $4^{\circ} \mathrm{C}$. Cells were then washed twice with $1 \times$ permeabilization buffer (eBioscience) and stained with PE anti-mouse/ rat Foxp3 antibody $\left(1 \mu \mathrm{g} / 1 \times 10^{6}\right.$ cells $)$ for $30 \mathrm{~min}$ at $4^{\circ} \mathrm{C}$. Finally, cells were washed twice in $1 \times$ permeabilization buffer. Cytometric data were acquired with Epics XL flow cytometer (Beckman Coulter, Brea, CA) and analyzed with CXP software version 2.2 (Beckman Coulter).

\section{Cytokine Assay}

Levels of IL-4, IL-6, IL-10, IL-17, IFN- $\gamma$ (eBioscience), and transforming growth factor (TGF)- $\beta 1$ (R\&D Systems, Minneapolis, MN) in cell culture supernatant and serum were measured by ELISA according to the manufacturer's instructions. The levels of TGF- $\beta 1$ in cell culture supernatants were measured after acid activation of samples; background TGF- $\beta 1$ levels in the cell culture medium itself were measured and subtracted from the values of test samples due to the cross-reactivity between murine and bovine TGF- $\beta 1$ present in FBS.

Table 1. Composition (\%) of the experimental diets

\begin{tabular}{lcc}
\hline Ingredient & Control diet & Cheese diet \\
\hline Cheese powder $^{1}$ & - & 43.9 \\
Casein & 20.0 & - \\
Cellulose & 5.0 & 5.0 \\
Corn oil & 2.1 & - \\
Lard & 17.3 & - \\
Sucrose & 49.8 & 45.9 \\
DL-Methionine & 0.3 & 0.3 \\
Vitamin mix (AIN-76) & 1.0 & 1.0 \\
Mineral mix (AIN-76) & 3.5 & - \\
Mineral mix (for cheese diet) & 3.5 \\
NaCl & - & 3.5 \\
CaHPO & 0.851 & - \\
$\mathrm{KH}_{2} \mathrm{PO}_{4}$ & 0.187 & - \\
$\mathrm{K}_{2} \mathrm{CO}_{3}$ & - & 0.015 \\
$\mathrm{MgO}_{\mathrm{FeC}} \mathrm{H}_{5} \mathrm{O}_{7}$ & - & 0.046 \\
$\mathrm{Ch}_{2}$ & - & 0.023 \\
& - & 0.374 \\
\hline
\end{tabular}

${ }^{1}$ Cheese powder $=45.6 \%$ protein, $44.2 \%$ fat, $5.9 \%$ ash, and $0.9 \%$ water. ${ }^{2}$ Casein $=87.5 \%$ protein, $0.9 \%$ fat, $1.8 \%$ ash, and $9.8 \%$ water.

${ }^{3}$ Mineral mix (for cheese diet): $5.2 \% \mathrm{~K}_{2} \mathrm{SO}_{4}, 0.35 \% \mathrm{MnCO}_{3}, 0.16 \%$ $\mathrm{ZnCO}_{3}, \quad 0.055 \% \quad \mathrm{CrK}\left(\mathrm{SO}_{4}\right)_{2} \cdot 12 \mathrm{H}_{2} \mathrm{O}, \quad 0.03 \% \quad \mathrm{CuCO}_{3} \cdot \mathrm{Cu}(\mathrm{OH})_{2} \cdot \mathrm{H}_{2} \mathrm{O}$, $0.001 \% \mathrm{Na}_{2} \mathrm{SeO}_{3} \cdot 5 \mathrm{H}_{2} \mathrm{O}, 0.001 \% \mathrm{KIO}_{3}$, and $94.203 \%$ sucrose. 


\section{Statistical Analysis}

Data are expressed as a mean \pm standard deviations. Statistical evaluations were performed by one-way ANOVA and Tukey-Kramer test for multiple comparisons or Student's $t$-test for single comparisons using StatView version 5.0 software (SAS Institute Inc., Cary, NC). Pvalues $<0.05$ were considered statistically significant.

\section{RESULTS}

\section{Effect of Cheese Diet on Immune Cell Response in Normal Mice}

Normal C57BL/6J mice were fed a cheese diet or the control diet for $5 \mathrm{wk}$; cytokine production and the ratio of $\mathrm{Foxp}^{+} \mathrm{CD}^{+} \mathrm{T}_{\text {reg }}$ to whole $\mathrm{CD} 4^{+}$cells in the spleen and Peyer's patch cells were then measured. In Peyer's patch cells, the production of IL-17, IL-4 and IL-10 was significantly lower in the cheese group than in the control group (Figure 1A, B, C) but the production of IFN- $\gamma$ did not differ between the 2 groups (Figure 1D). In the spleen cells, levels of all the cytokines measured were not affected by consumption of the cheese-containing diet (Figure 1A-D). The ratio of Foxp $3^{+} \mathrm{CD} 4^{+} \mathrm{T}_{\text {reg }}$ to whole $\mathrm{CD} 4^{+}$cells in Peyer's patch cells was significantly higher in the cheese group than in the control group, whereas the ratio in spleen did not differ significantly between the 2 groups (Figure 2).
A

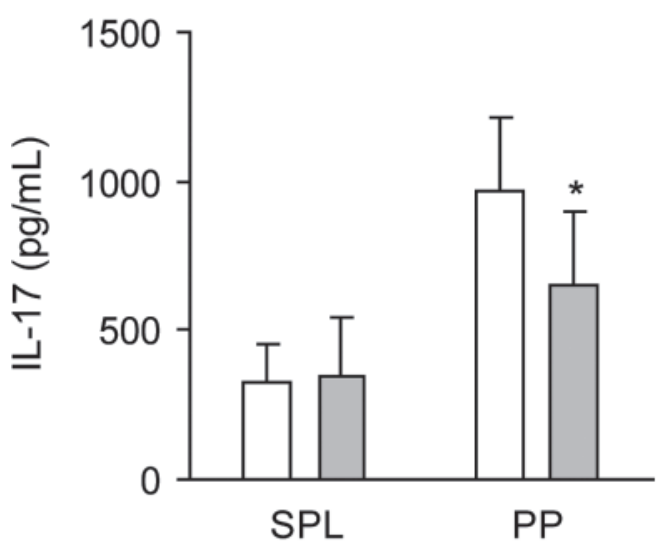

C

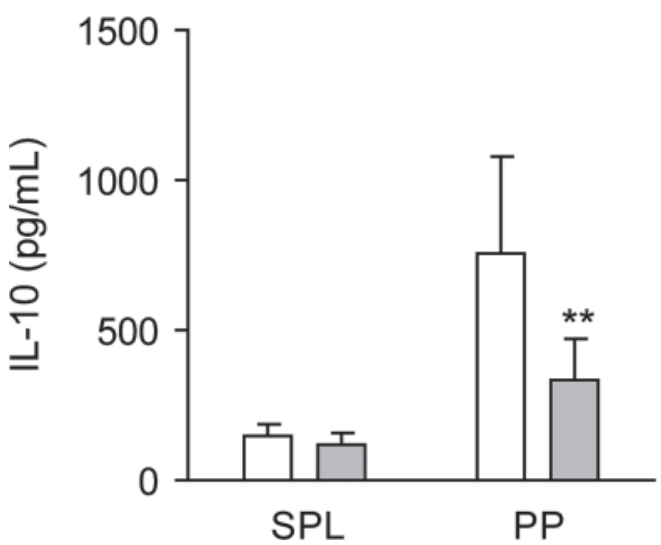

B

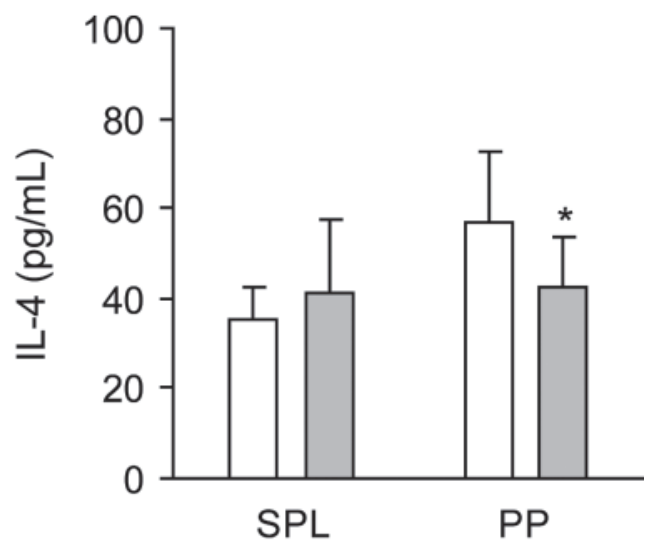

D

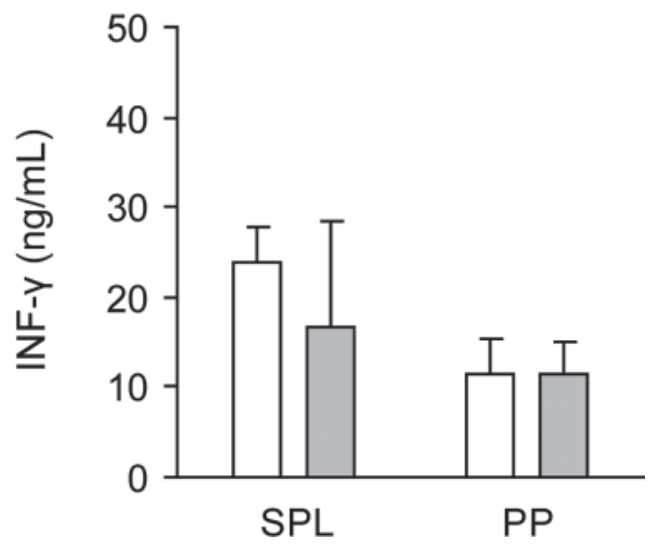

Figure 1. Effect of cheese diet on cytokine production in the spleen (SPL) and Peyer's patch (PP) cells of normal mice. Cells were isolated from mice fed the control diet or the cheese diet and stimulated with anti-CD3/CD28-conjugated beads. After 48 to $72 \mathrm{~h}$ of stimulation, levels of (A) IL-17, (B) IL-4, (C) IL-10, and (D) IFN- $\gamma$ in cell culture supernatants were measured by an ELISA. Data are expressed as a mean \pm SD $(\mathrm{n}=10)$ and compared with the control group (Student's $t$-test; ${ }^{*} P<0.05,{ }^{* *} P<0.01$ ). 


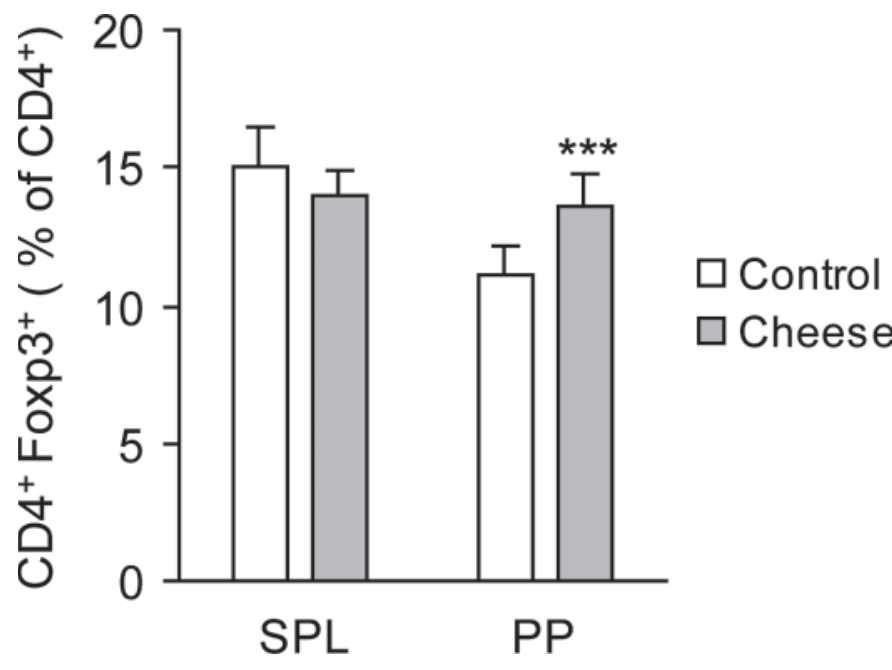

Figure 2. Effect of cheese diet on the population of Foxp $3^{+} \mathrm{CD} 4^{+}$ cells in the spleen (SPL) and Peyer's patch (PP) of normal mice. Cells were isolated from mice fed the control diet or the cheese diet and analyzed for CD4 and Foxp3 expression by flow cytometry. The bars represent the ratio of $\mathrm{Foxp}^{+} \mathrm{CD} 4^{+}$cells to whole $\mathrm{CD} 4^{+}$cells. Data are expressed as means $\pm \mathrm{SD}(\mathrm{n}=10)$ and compared with the control group $(* * * P<0.001)$ by Student's $t$-test.

\section{Effect of Cheese Diet on DSS-Induced Colitis}

The effect of consumption of the cheese-containing diet on DSS-induced colitis was examined. Significant BW loss was observed from d 4 in the DSS group but not observed in the DSS + cheese group (Figure 3A). The DAI score based on BW loss, stool consistency, and bleeding was significantly lower in the DSS + cheese group than in the DSS group (Figure 3B). Colon length was significantly decreased in the DSS group compared with the non-DSS group, and the DSS + cheese group showed significantly greater colon length compared with the DSS group (Figure 3C, D).

\section{Effect of Cheese Diet on Immune Cell Response in DSS-Induced Colitis Mice}

Representative proinflammatory (IL-17 and IL-6) and antiinflammatory (TGF- $\beta 1$ and IL-10) cytokines, and the ratio of Foxp $3^{+} \mathrm{CD} 4^{+} \mathrm{T}_{\text {reg }}$ to whole $\mathrm{CD} 4^{+}$cells in the spleen and Peyer's patch were measured. Production of IL-17 in both the spleen and Peyer's patch cells was significantly greater in the DSS group compared with the non-DSS group. Production of IL-17 in the DSS group was significantly decreased in the Peyer's patch cells of the DSS + cheese group (Figure 4A).

Production of IL-6 in the spleen cells was significantly lower in the DSS group compared with the non-DSS group. In the DSS + cheese group, IL-6 levels were the same as those observed in the non-DSS group. Production of IL-6 in Peyer's patch cells was significantly higher in the DSS group compared with the non-DSS group; this elevated IL-6 production in the DSS group was significantly reduced in the DSS + cheese group (Figure 4B).

Production of TGF- $\beta 1$ in both the spleen and Peyer's patch cells did not differ between the non-DSS group and the DSS group; production in both the spleen and Peyer's patch cells was significantly increased in the DSS + cheese group compared with the DSS group (Figure 4C).

Production of IL-10 in the spleen cells did not differ among the groups. In Peyer's patch cells, IL-10 production was significantly higher in the DSS group compared with the non-DSS group; however, production in the DSS + cheese group did not differ compared with the other groups (Figure 4D).

The ratio of Foxp $3^{+} \mathrm{CD} 4^{+} \mathrm{T}_{\text {reg }}$ to whole $\mathrm{CD} 4^{+}$cells in both the spleen and Peyer's patch cells was significantly higher in the DSS group than in the non-DSS (control) group. The elevated $\mathrm{T}_{\text {reg }}$ populations observed in the DSS group were significantly reduced in the DSS + cheese group (Figure 5).

\section{DISCUSSION}

The present study investigated differential immune responses in normal mice and mice with DSS-induced colitis fed 2 different diets, one containing a relatively high amount of cheese (approximately 44\%) and the other containing casein, lard, and corn oil as the control. The spleen and Peyer's patch cells were used to evaluate $T_{\text {reg }}$ induction and several representative cytokines.

In normal mice, consumption of the cheese-containing diet elevated the $\mathrm{T}_{\text {reg }}$ population and decreased production of IL-17, IL-4, and IL-10 in Peyer's patch cells. However, consumption of the cheese-containing diet did not affect $\mathrm{T}_{\text {reg }}$ induction or cytokine production in spleen cells, suggesting that consumption of the cheesecontaining diet induced a regulatory function in the intestine.

The cheese diet-induced increase in $T_{\text {reg }}$ population, observed in the Peyer's patch cells of normal mice, might lead to reduced production of IL-4 and, in particular, IL-17, a proinflammatory cytokine produced by a particular T-cell subset named Th17 cells (Harrington et al., 2005; Park et al., 2005). One explanation for this is the fact that Th17 cells and $\mathrm{T}_{\text {reg }}$ functionally antagonize each other and their differentiation processes are interconnected and probably competitive in utilizing naïve $\mathrm{T}$ cells as precursors (Bettelli et al., 2006; Mangan et al., 2006). Although the primary function of Th17 cells is host defense against extracellular pathogens, Th17 cells are involved in the pathogenesis of inflammatory and autoimmune diseases, including IBD (Tesmer et 
al., 2008). An imbalance between Th17 cells and $\mathrm{T}_{\text {reg }}$ has been demonstrated in IBD patients (Eastaff-Leung et al., 2010); Th17 cells also play a central role in a mouse model of DSS-induced colitis that resembles human IBD, especially ulcerative colitis (Ito et al., 2008).

Our data show that $\mathrm{T}_{\text {reg }}$ were increased in the Peyer's patch cells of normal mice fed the cheese-containing diet, whereas IL-10 production was reduced, although IL-10 is known to be secreted by $\mathrm{T}_{\text {reg }}$ to suppress the functions of other $\mathrm{T}$ cells (Sakaguchi et al., 2009). Such inconsistency observed in our data between the induction of $\mathrm{T}_{\text {reg }}$ and lack of increase in IL-10 might be explained by the involvement of other types of cells in Peyer's patches: non- $T$ cells such as dendritic cells, macrophages, and B cells, which can also produce IL10 (Borish, 1998). A possible explanation is that $\mathrm{T}_{\mathrm{reg}}$ induced by consumption of the cheese-containing diet might affect the non- $\mathrm{T}$ cells, suppressing their IL-10 production, resulting in a decrease in IL-10 levels in the whole Peyer's patch cell culture. In addition, because the $\mathrm{T}_{\text {reg }}$ population in Peyer's patch cells is relatively minor compared with the non-T cells, IL-10 produced by $\mathrm{T}_{\mathrm{reg}}$ might not be reflected in the IL-10 levels in the Peyer's patch cell culture.

Symptoms of DSS-induced colitis were alleviated in the cheese-containing diet group, as evidenced by the prevention of BW loss, lowering of DAI score, and prevention of colon length shortening. The alleviated symptoms are also supported by our supplementary information (data not shown here): the cheese-containing diet group had less compromised intestinal wall, as observed in a hematoxylin-stained specimen, and lower
A

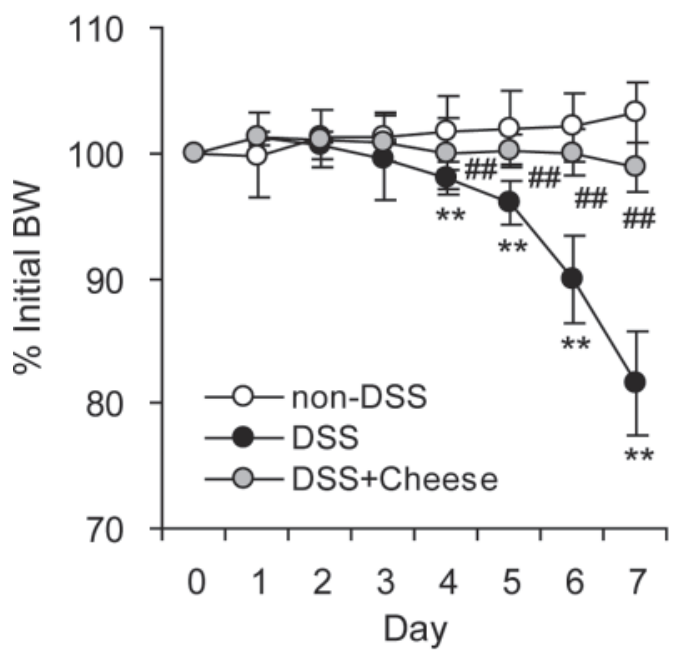

C

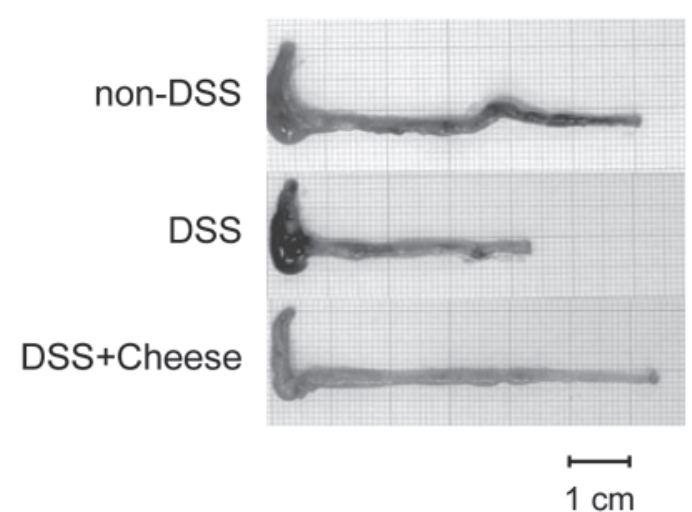

B

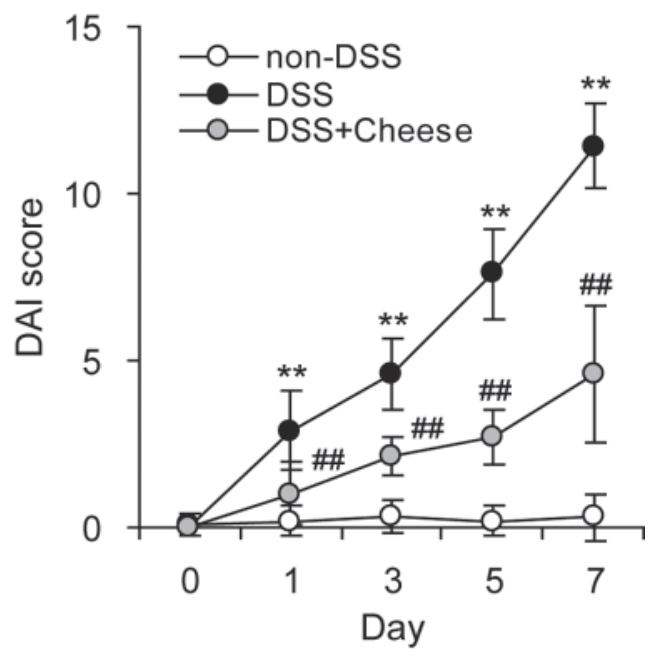

D

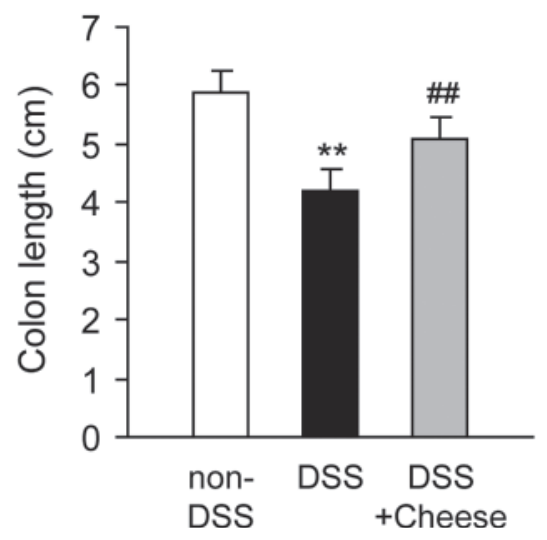

Figure 3. Effect of cheese diet on dextran sodium sulfate (DSS)-induced colitis. Mice were divided into 3 groups: DSS-untreated mice fed the control diet (non-DSS), DSS-treated mice fed the control diet (DSS), and DSS-treated mice fed the cheese diet (DSS + cheese). The DSS and DSS + cheese groups were treated with $2 \%$ (wt/vol) DSS for $7 \mathrm{~d}$ to induce colitis. (A) BW; (B) disease activity index (DAI); (C) macroscopic appearance of a representative colon; and (D) colon length. Data are expressed as means \pm SD $(n=10)$ and compared with the non-DSS group $(* * P<0.01)$ or with the DSS group $(\# \# P<0.01)$ by the Tukey-Kramer test. 


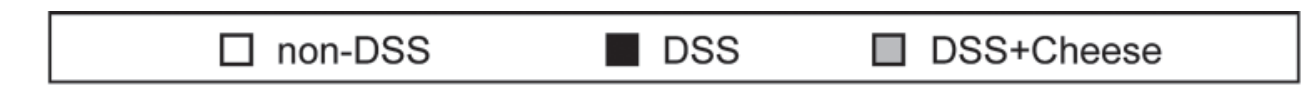

A

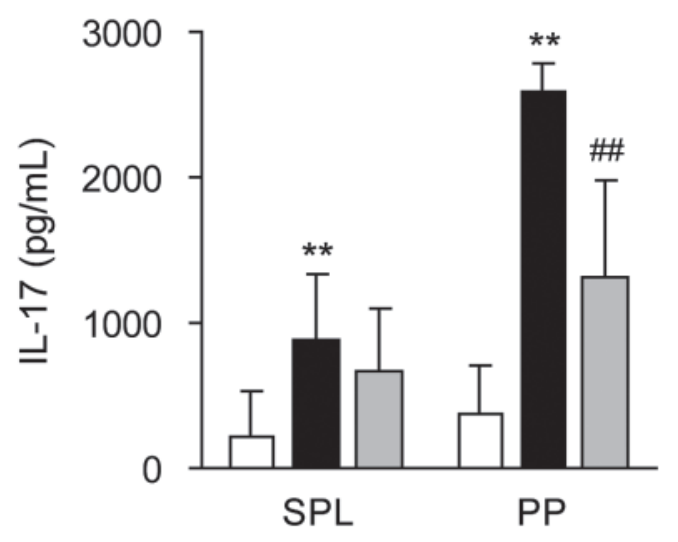

C

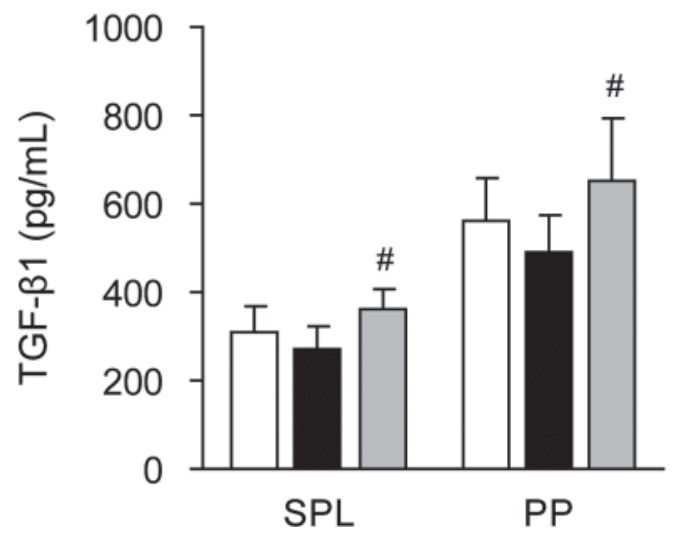

B
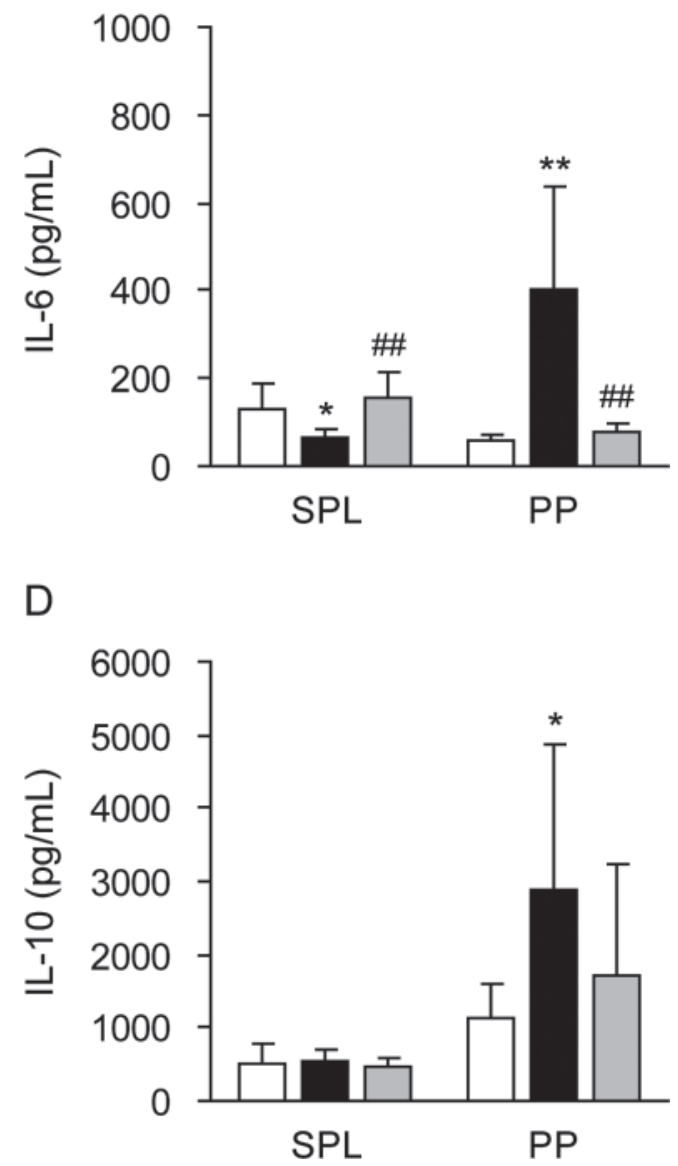

Figure 4. Effect of cheese diet on cytokine production in the spleen (SPL) and Peyer's patch (PP) cells in mice with dextran sodium sulfate (DSS)-induced colitis. Seven days after the administration of DSS, SPL and PP cells were isolated and stimulated with anti-CD3/CD28conjugated beads. After 48 to $72 \mathrm{~h}$ of stimulation, levels of (A) IL-17, (B) IL-6, (C) transforming growth factor (TGF)- $\beta 1$, and (D) IL-10 in cell culture supernatants were measured by an ELISA. Data are expressed as means \pm SD $(\mathrm{n}=10)$ and compared with the non-DSS group $(* P<$ 0.05 and $\left.{ }^{* *} P<0.01\right)$ or with the DSS group $(\# P<0.05$ and \#\#P<0.01) by the Tukey-Kramer test.

serum IL-6 levels; serum levels of IL-6 are known to correlate with disease severity in IBD patients (Mudter and Neurath, 2007).

Ingestion of DSS elevated the production of IL-17 and IL-6, which are proinflammatory cytokines involved in intestinal inflammation (Naito et al., 2004), in Peyer's patch cells; however, IL-17 and IL-6 were reduced in the cheese-containing diet group, suggesting an antiinflammatory effect of consumption of the cheese-containing diet.

In contrast to the IL-17 and IL-6 elevations, ingestion of DSS did not affect the production of TGF- $\beta 1$ in Peyer's patch cells or spleen cells, whereas the level of TGF- $\beta 1$ was elevated in the cheese-containing diet group. Transforming growth factor- $\beta 1$ is a multifunctional cytokine, regulating proliferation, differentia- tion, and the function of immune and nonimmune cells (Takenoshita et al., 2002; Li et al., 2006). It also plays a critical role in intestinal epithelial restitution after mucosal injury (Dignass and Podolsky, 1993), and disruption of TGF- 31 signaling is associated with the development of colitis in mice (Hahm et al., 2001). Considering that DSS-induced colitis disrupts the intestinal barrier function by increasing apoptosis and decreasing proliferation of the intestinal epithelial cells (Araki et al., 2010), the elevation of TGF- $\beta 1$ might help repair the intestinal damage caused by DSS.

Ingestion of DSS elevated the $T_{\text {reg }}$ population in both the spleen and Peyer's patch cells. We consider this elevation to be a protective response of the body to DSS-induced colitis. In IBD patients, for example, $\mathrm{T}_{\text {reg }}$ are increased in the inflamed intestine and their popu- 
lations are positively correlated with disease activities; the $\mathrm{T}_{\text {reg }}$ isolated from the intestines of IBD patients have been shown to possess suppressive functions in vitro (Kelsen et al., 2005; Holmén et al., 2006).

The DSS-induced increase in $\mathrm{T}_{\text {reg }}$ population, which was substantial compared with that in the non-DSS group, was reduced significantly in the cheese-containing diet group (DSS + cheese). We suggest that this reduction was due to the alleviation of colitis, given that alleviated colitis should require less protective responses. In addition, the alleviated colitis might relate to the reduced production of proinflammatory cytokines (IL-17 and IL-6) and enhanced production of TGF- $\beta 1$ in mice with DSS-induced colitis, as described above. However, further work is required to determine whether $\mathrm{T}_{\text {reg }}$ acted directly to relieve colitis or whether changes in the $T_{\text {reg }}$ population only reflected the status of colitis. A possible way to examine the actual role of $\mathrm{T}_{\text {reg }}$ induced by cheese consumption might be a cell transfer experiment, because studies have shown that transfer of $\mathrm{T}_{\text {reg }}$ can prevent development of colitis (Liu et al., 2003; Mottet et al., 2003; Huber et al., 2004).

Various food components have been reported to alleviate colitis: the amino acid glutamine has been shown to reduce chemically induced colitis (Ameho et al., 1997), dietary conjugated linoleic acid and n-3 PUFA can reduce inflammation (Bassaganya-Riera and Hontecillas, 2010), and whey protein (Sprong et al., 2010) and lactoperoxidase from bovine milk (Shin et al., 2009) can ameliorate DSS-induced colitis. In addition, some components in the diet may chemically interact with negatively charged DSS, which might affect the toxicity

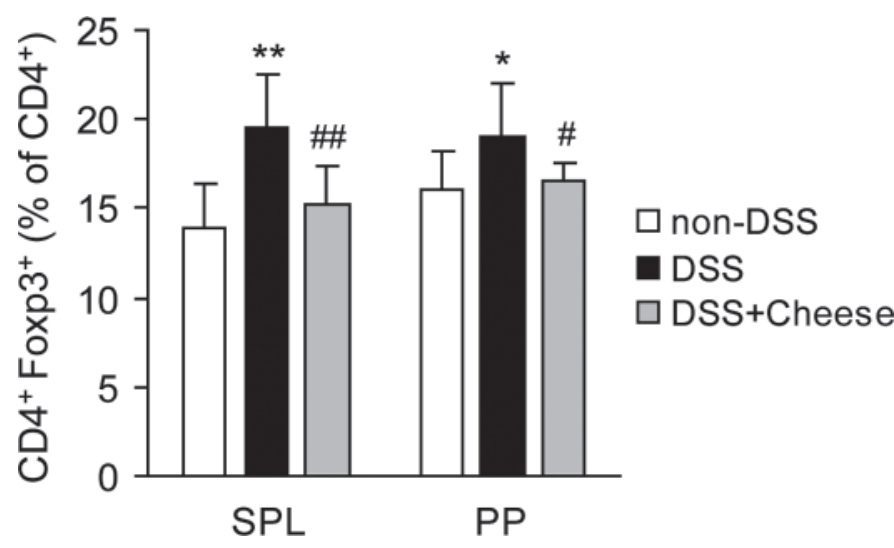

Figure 5. Effect of cheese diet on the population of Foxp $3^{+} \mathrm{CD} 4^{+}$ cells in the spleen (SPL) and Peyer's patch (PP) cells in mice with dextran sodium sulfate (DSS)-induced colitis. Seven days after the administration of DSS, SPL and PP cells were isolated and analyzed for CD4 and Foxp3 expression by flow cytometry. The bars represent the ratio of Foxp $3^{+} \mathrm{CD} 4^{+}$cells to whole $\mathrm{CD} 4^{+}$cells. Data are expressed as means $\pm \mathrm{SD}(\mathrm{n}=10)$ and compared with the non-DSS group $\left({ }^{*} P<\right.$ 0.05 and $\left.{ }^{* *} P<0.01\right)$ or with the DSS group $(\# P<0.05$ and \#\#P< 0.01 ) by the Tukey-Kramer test. of DSS. However, because of limitations of our experimental design, one of which was the large difference in fatty acid composition between the control and cheese diets, the present study could not provide specific information about possible components contributing to the immunomodulatory and colitis-alleviating effects, which remain to be examined in the future.

\section{CONCLUSIONS}

Consumption of the cheese-containing diet produced immunomodulatory effects compared with the control diet, including induction of $\mathrm{T}_{\text {reg }}$ and suppression of cytokine production (IL-17, IL-4, and IL-10) in Peyer's patch cells from normal mice. In a mouse model of DSS-induced colitis, consumption of the cheese-containing diet demonstrated a reduced production of proinflammatory cytokines (IL-17 and IL-6) and enhanced production of TGF- $\beta 1$ in Peyer's patch cells, accompanied by a decrease in the $\mathrm{T}_{\text {reg }}$ population, which might reflect alleviation of symptoms of colitis. Collectively, these findings indicated that consumption of the cheese-containing diet enhanced antiinflammatory and immune regulatory responses in normal mice and a DSS-colitis mouse model.

\section{REFERENCES}

Ameho, C. K., A. A. Adjei, E. K. Harrison, K. Takeshita, T. Morioka, Y. Arakaki, E. Ito, I. Suzuki, A. D. Kulkarni, A. Kawajiri, and S. Yamamoto. 1997. Prophylactic effect of dietary glutamine supplementation on interleukin 8 and tumour necrosis factor alpha production in trinitrobenzene sulphonic acid induced colitis. Gut 41:487-493.

American Institute of Nutrition. 1977. Report of the American Institute of Nutrition ad hoc committee on standards for nutritional studies. J. Nutr. 107:1340-1348.

Araki, Y., K. Mukaisyo, H. Sugihara, Y. Fujiyama, and T. Hattori. 2010. Increased apoptosis and decreased proliferation of colonic epithelium in dextran sulfate sodium-induced colitis in mice. Oncol. Rep. 24:869-874.

Ariake, K., T. Ohkusa, T. Sakurazawa, J. Kumagai, Y. Eishi, S. Hoshi, and T. Yajima. 2000. Roles of mucosal bacteria and succinic acid in colitis caused by dextran sulfate sodium in mice. J. Med. Dent. Sci. 47:233-241.

Asakura, H., K. Suzuki, T. Kitahora, and T. Morizane. 2008. Is there a link between food and intestinal microbes and the occurrence of Crohn's disease and ulcerative colitis? J. Gastroenterol. Hepatol. 23:1794-1801.

Bassaganya-Riera, J., and R. Hontecillas. 2010. Dietary conjugated linoleic acid and n-3 polyunsaturated fatty acids in inflammatory bowel disease. Curr. Opin. Clin. Nutr. Metab. Care 13:569-573.

Bettelli, E., Y. Carrier, W. Gao, T. Korn, T. B. Strom, M. Oukka, H L. Weiner, and V. K. Kuchroo. 2006. Reciprocal developmental pathways for the generation of pathogenic effector TH17 and regulatory T cells. Nature 441:235-238.

Borish, L. 1998. IL-10: Evolving concepts. J. Allergy Clin. Immunol. 101:293-297.

Dignass, A. U., and D. K. Podolsky. 1993. Cytokine modulation of intestinal epithelial cell restitution: Central role of transforming growth factor beta. Gastroenterology 105:1323-1332. 
Eastaff-Leung, N., N. Mabarrack, A. Barbour, A. Cummins, and S. Barry. 2010. Foxp $3^{+}$regulatory T cells, Th17 effector cells, and cytokine environment in inflammatory bowel disease. J. Clin. Immunol. 30:80-89.

Fontenot, J. D., M. A. Gavin, and A. Y. Rudensky. 2003. Foxp3 programs the development and function of $\mathrm{CD} 4{ }^{+} \mathrm{CD} 25^{+}$regulatory $\mathrm{T}$ cells. Nat. Immunol. 4:330-336.

Goh, K., and S. D. Xiao. 2009. Inflammatory bowel disease: A survey of the epidemiology in Asia. J. Dig. Dis. 10:1-6.

Gómez-Ruiz, J. A., M. Ramos, and I. Recio. 2004. Angiotensin converting enzyme-inhibitory activity of peptides isolated from Manchego cheese. Stability under simulated gastrointestinal digestion. Int. Dairy J. 14:1075-1080.

Hahm, K. B., Y. H. Im, T. W. Parks, S. H. Park, S. Markowitz, H. Y. Jung, J. Green, and S. J. Kim. 2001. Loss of transforming growth factor beta signalling in the intestine contributes to tissue injury in inflammatory bowel disease. Gut 49:190-198.

Hanauer, S. B. 2006. Inflammatory bowel disease: Epidemiology, pathogenesis, and therapeutic opportunities. Inflamm. Bowel Dis. 12:S3-S9.

Harrington, L. E., R. D. Hatton, P. R. Mangan, H. Turner, T. L. Murphy, K. M. Murphy, and C. T. Weaver. 2005. Interleukin 17-producing $\mathrm{CD}^{+}$effector $\mathrm{T}$ cells develop via a lineage distinct from the $\mathrm{T}$ helper type 1 and 2 lineages. Nat. Immunol. 6:1123-1132.

Higurashi, S., Y. Kunieda, H. Matsuyama, and H. Kawakami. 2007. Effect of cheese consumption on the accumulation of abdominal adipose and decrease in serum adiponectin levels in rats fed a calorie dense diet. Int. Dairy J. 17:1224-1231.

Holmén, N., A. Lundgren, S. Lundin, A. M. Bergin, A. Rudin, H. Sjovall, and L. Ohman. 2006. Functional CD $4{ }^{+} \mathrm{CD} 25^{\text {high }}$ regulatory $\mathrm{T}$ cells are enriched in the colonic mucosa of patients with active ulcerative colitis and increase with disease activity. Inflamm. Bowel Dis. 12:447-456.

Hori, S., T. Nomura, and S. Sakaguchi. 2003. Control of regulatory $\mathrm{T}$ cell development by the transcription factor Foxp3. Science 299:1057-1061.

Huber, S., C. Schramm, H. A. Lehr, A. Mann, S. Schmitt, C. Becker, M. Protschka, P. R. Galle, M. F. Neurath, and M. Blessing. 2004 Cutting edge: TGF-beta signaling is required for the in vivo expansion and immunosuppressive capacity of regulatory $\mathrm{CD} 4^{+} \mathrm{CD} 25^{+} \mathrm{T}$ cells. J. Immunol. 173:6526-6531.

Ito, R., M. Kita, M. Shin-Ya, T. Kishida, A. Urano, R. Takada, J. Sakagami, J. Imanishi, Y. Iwakura, T. Okanoue, T. Yoshikawa, K. Kataoka, and O. Mazda. 2008. Involvement of IL-17A in the pathogenesis of DSS-induced colitis in mice. Biochem. Biophys. Res. Commun. 377:12-16.

Kelsen, J., J. Agnholt, H. J. Hoffmann, J. L. Romer, C. L. Hvas, and J. F. Dahlerup. 2005. FoxP3(+)CD4(+)CD25(+) T cells with regulatory properties can be cultured from colonic mucosa of patients with Crohn's disease. Clin. Exp. Immunol. 141:549-557.

Kitajima, S., S. Takuma, and M. Morimoto. 1999. Tissue distribution of dextran sulfate sodium (DSS) in the acute phase of murine DSSinduced colitis. J. Vet. Med. Sci. 61:67-70.

Li, M. O., Y. Y. Wan, S. Sanjabi, A. K. Robertson, and R. A. Flavell. 2006. Transforming growth factor-beta regulation of immune responses. Annu. Rev. Immunol. 24:99-146.

Liu, H., B. Hu, D. Xu, and F. Y. Liew. 2003. CD $4^{+} \mathrm{CD} 25^{+}$regulatory T cells cure murine colitis: The role of IL-10, TGF-beta, and CTLA4. J. Immunol. 171:5012-5017.

Mangan, P. R., L. E. Harrington, D. B. O'Quinn, W. S. Helms, D. C. Bullard, C. O. Elson, R. D. Hatton, S. M. Wahl, T. R. Schoeb, and C. T. Weaver. 2006. Transforming growth factor-beta induces development of the $\mathrm{T}(\mathrm{H}) 17$ lineage. Nature 441:231-234.

Mchenga, S. S., D. Wang, C. Li, F. Shan, and C. Lu. 2008. Inhibitory effect of recombinant IL-25 on the development of dextran sulfate sodium-induced experimental colitis in mice. Cell. Mol. Immunol. $5: 425-431$.

Mottet, C., H. H. Uhlig, and F. Powrie. 2003. Cutting edge: Cure of colitis by $\mathrm{CD} 4{ }^{+} \mathrm{CD} 25^{+}$regulatory T cells. J. Immunol. 170:39393943

Mudter, J., and M. F. Neurath. 2007. Il-6 signaling in inflammatory bowel disease: Pathophysiological role and clinical relevance. Inflamm. Bowel Dis. 13:1016-1023.

Naito, Y., T. Takagi, K. Uchiyama, M. Kuroda, S. Kokura, H. Ichikawa, R. Yanagisawa, K. Inoue, H. Takano, M. Satoh, N. Yoshida, T. Okanoue, and T. Yoshikawa. 2004. Reduced intestinal inflammation induced by dextran sodium sulfate in interleukin-6-deficient mice. Int. J. Mol. Med. 14:191-196.

National Research Council. 1996. Guide for the Care and Use of Laboratory Animals. National Academy Press, Washington, DC.

Okayasu, I., S. Hatakeyama, M. Yamada, T. Ohkusa, Y. Inagaki, and R. Nakaya. 1990. A novel method in the induction of reliable experimental acute and chronic ulcerative colitis in mice. Gastroenterology 98:694-702.

Park, H., Z. Li, X. O. Yang, S. H. Chang, R. Nurieva, Y. H. Wang, Y Wang, L. Hood, Z. Zhu, Q. Tian, and C. Dong. 2005. A distinct lineage of $\mathrm{CD} 4 \mathrm{~T}$ cells regulates tissue inflammation by producing interleukin 17. Nat. Immunol. 6:1133-1141.

Persson, P. G., A. Ahlbom, and G. Hellers. 1992. Diet and inflammatory bowel disease: A case-control study. Epidemiology 3:47-52.

Reif, S., I. Klein, F. Lubin, M. Farbstein, A. Hallak, and T. Gilat 1997. Pre-illness dietary factors in inflammatory bowel disease. Gut 40:754-760.

Saito, T., T. Nakamura, H. Kitazawa, Y. Kawai, and T. Itoh. 2000 Isolation and structural analysis of antihypertensive peptides that exist naturally in Gouda cheese. J. Dairy Sci. 83:1434-1440.

Sakaguchi, S., M. Ono, R. Setoguchi, H. Yagi, S. Hori, Z. Fehervari, J. Shimizu, T. Takahashi, and T. Nomura. 2006. Foxp $3^{+}$CD $25^{+}$ $\mathrm{CD}^{+}$natural regulatory $\mathrm{T}$ cells in dominant self-tolerance and autoimmune disease. Immunol. Rev. 212:8-27.

Sakaguchi, S., K. Wing, Y. Onishi, P. Prieto-Martin, and T. Yamaguchi. 2009. Regulatory T cells: How do they suppress immune responses? Int. Immunol. 21:1105-1111.

Sakamoto, N., S. Kono, K. Wakai, Y. Fukuda, M. Satomi, T. Shimoyama, Y. Inaba, Y. Miyake, S. Sasaki, K. Okamoto, G. Kobashi, M. Washio, T. Yokoyama, C. Date, and H. Tanaka. 2005. Dietary risk factors for inflammatory bowel disease: A multicenter case-control study in Japan. Inflamm. Bowel Dis. 11:154-163.

Shin, K., A. Horigome, K. Yamauchi, T. Yaeshima, and K. Iwatsuki. 2009. Orally administered lactoperoxidase ameliorates dextran sulfate sodium-induced colitis in mice by up-regulating colonic interleukin-10 and maintaining peripheral regulatory $\mathrm{T}$ cells. Int. Immunopharmacol. 9:1387-1393.

Sprong, R. C., A. J. Schonewille, and R. van der Meer. 2010. Dietary cheese whey protein protects rats against mild dextran sulfate sodium-induced colitis: Role of mucin and microbiota. J. Dairy Sci. 93:1364-1371.

Takenoshita, S., T. Fukushima, K. Kumamoto, and M. Iwadate. 2002. The role of TGF-beta in digestive organ disease. J. Gastroenterol. 37:991-999.

Tan, P., M. Sasaki, B. W. Bosman, and T. Iwasaki. 1995. Purification and characterization of a dipeptidase from Lactobacillus helveticus SBT 2171. Appl. Environ. Microbiol. 61:3430-3435.

Tesmer, L. A., S. K. Lundy, S. Sarkar, and D. A. Fox. 2008. Th17 cells in human disease. Immunol. Rev. 223:87-113.

Trickett, A., and Y. L. Kwan. 2003. T cell stimulation and expansion using anti-CD3/CD28 beads. J. Immunol. Methods 275:251-255.

Walther, B., A. Schmid, R. Sieber, and K. Wehrmuller. 2008. Cheese in nutrition and health. Dairy Sci. Technol. 88:389-405. 